\title{
SOLVENT FREE SYNTHESIS OF MALONYL CHLORIDES: A GREEN CHEMISTRY APPROACH
}

\author{
Manjusha R. Patil ${ }^{1}$, S. M. Chavan ${ }^{2}$ \\ ${ }^{1}$ Department of Chemical Engg, Sinhgad College of Engineering, Pune, Maharashtra, India \\ ${ }^{2}$ HOD, Department of Chemical Engg, Sinhgad College of Engineering, Pune, Maharashtra, India
}

\begin{abstract}
Methyl malonyl chloride and ethyl malonyl chloride are the acid chlorides of malonic acid diester. The present study focuses on the study of the synthesis of monomethyl malonyl chloride and monoethyl malonyl chloride. The synthesis was a three step process of selective saponification of dialkyl malonate followed by hydrolysis and then chlorination of monoalkyl malonic acid. The reaction was studied in the presence of solvent and absence of solvent (which is methylene chloride). Kinetics of the process was studied. Reaction was found to be first order by integrated rate law. The green process was evaluated with maximum conversion. The conversion of methyl malonic acid in solvent process was found to be $78.67 \%$ and in without solvent process was found to be 93.08\% from the experiments carried out. The conversion of ethyl malonic acid in solvent process was found to be $84.39 \%$ and in without solvent process was found to be $98.23 \%$ from the experiments carried out.
\end{abstract}

Keywords: Green chemistry, methyl malonyl chloride, ethyl malonyl chloride, malonic acid. $* * *$

\section{INTRODUCTION}

Methyl malonyl chloride and ethyl malonyl chloride are the acid chlorides of malonic acid diester [1]. Malonyl chloride and substituted malonyl chlorides were found to be a very good precursor for organic synthesis especially in malonic acid derivatives and heterocyclic derivatives.

The procedure reported for the preparation of monomethyl malonyl chloride uses methylene chloride as solvent. Carbomethoxy acetic acid is dissolved in methylene dichloride. Thionyl chloride is added. The exothermicity of the process is little. Then the reaction mass is refluxed for 1 hour at $40-45^{\circ} \mathrm{C}$. Then methylene dichloride is distilled out to give carbomethoxy acetyl chloride [2].

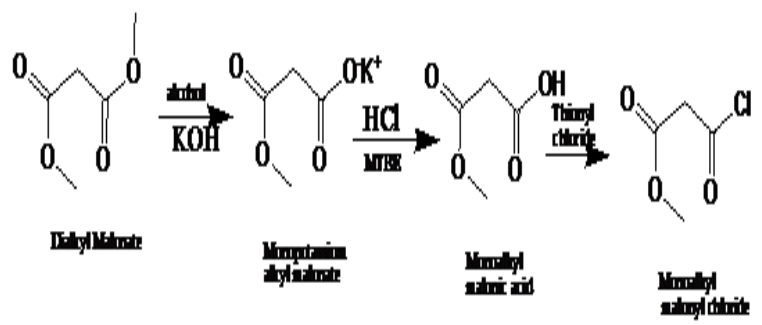

Fig 1: Scheme of synthesis of monoalkyl malonyl chloride from dialkyl malonate.

In the present work, the alkyl group represents the methyl and ethyl group. The malonyl chlorides are prepared in a 3 step process as shown in Figure 1. In the first step, the starting material dialkyl malonate is converted to monopotassium salt of diester by reacting with Potassium hydroxide in alcoholic medium. Potassium salt of monoalkyl malonate is relatively more stable and suitable for commercial manufacturing [3] [4]. In step 2, potassium salt of monoalkyl malonate is hydrolysed using conc. $\mathrm{HCl}$ to give monoalkyl malonic acid [2]. In step 3, the monoalkyl malonic acid is reacted with a suitable chlorinating agent like thionyl chloride [2]. The product obtained is monoalkyl malonyl chloride. Since the byproducts (impurities) are not produced, the isolation cost is reduced. Thionyl chloride used in excess can be recovered by distillation and can be recycled. The side products $\left(\mathrm{HCl}\right.$ and $\left.\mathrm{SO}_{2}\right)$ are gaseous which can be removed by scrubbing.

The thionyl chloride replaces the $\mathrm{OH}$ group by $\mathrm{Cl}$, forming an acid chloride. This is the only method by which malonyl chloride can be prepared, since other chlorinating agents like phosphorus pentachloride converts malonic acid into carbon suboxide[5].

In this work the main aim was to investigate the rate of reaction of the process in the solvent environment and in the solvent free environment, find order of reaction and to study the process in green chemistry aspect i.e., to make the process solvent free [6].

\section{EXPERIMENTAL PROCEDURE}

\subsection{Preparation of Monoalkyl Malonyl Chloride}

\section{from Monoalkyl Malonic Acid}

\subsubsection{Experimental Set Up:}

The chlorination of the acid required a moisture proof atmosphere. The experimental work was strictly carried out in a hood. A guard tube was used so as to avoid the moisture to enter into the reaction mass. The equipments used are round bottom flask along with thermowell, stirrer, condenser and a dropping funnel for the addition of thionyl chloride. It was provided with the heating mantle. 


\subsubsection{Experimental Procedure (With Solvent)}

Monoester monoacid was reacted with thionyl chloride in the molar ratio of 1:2 in the presence of solvent, methylene choride at $40-45^{\circ} \mathrm{C}$. Volume ratio of solvent to acid was $1: 4$. The reaction mass for refluxed for 1 hour. Product was isolated by distillation of solvent under vacuum. It was followed by high vacuum distillation to ensure complete removal of solvent.

\subsubsection{Experimental Procedure (Without Solvent)}

Monoester monoacid was reacted with thionyl chloride in the molar ratio of 1:2. The reaction mass is refluxed for 1 hour at $40-45^{\circ} \mathrm{C}$. Product is isolated by distillation of excess thionyl chloride.

Thin layer chromatographic techniques were used to separate the components of a mixture using a thin stationary phase supported by an inert backing. Proper solvent selection is perhaps the most important aspect of TLC and determining the best solvent may require a degree of trial and error [7].

Samples of monoalkyl malonic acid of known concentration were prepared as follows. Concentration in grams was diluted in $10 \mathrm{ml}$ of ethyl acetate. Then the sample was spotted on the TLC plate. The mobile phase used for TLC was hexane:ethyl acetate (50:50). The calibration curve for monomethyl malonic acid is shown in Figure 2. The calibration curve for monoethyl malonic acid is shown in Figure 3.

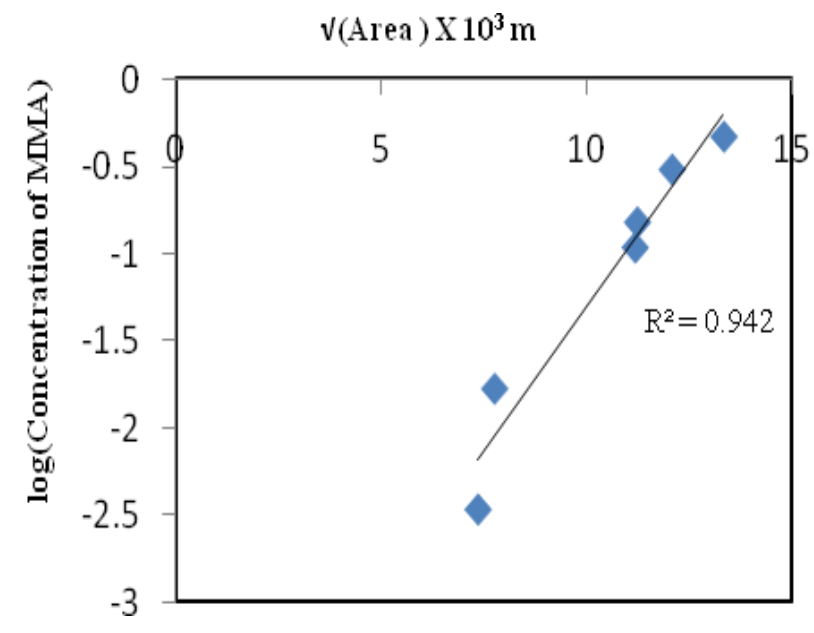

Fig 2: Calibration curve for methyl malonic acid

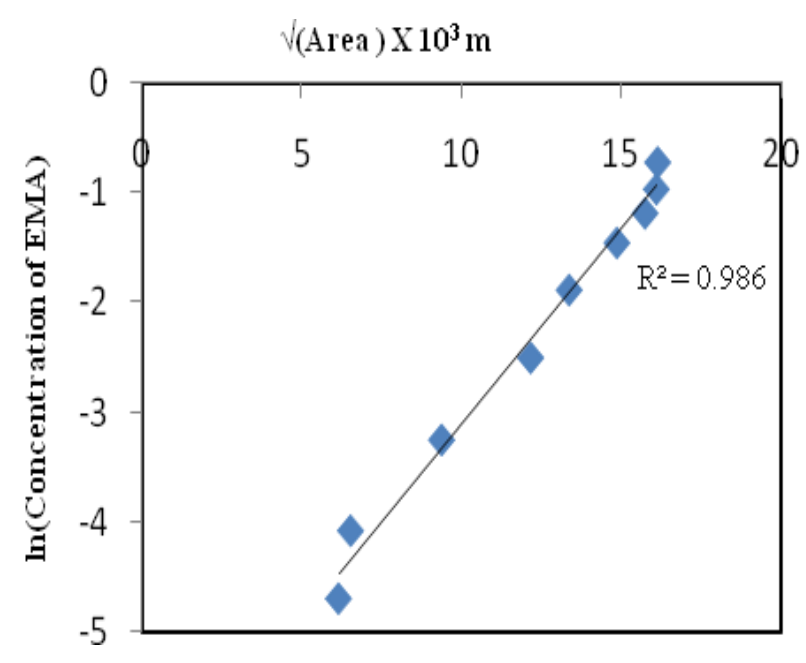

Fig 3: Calibration curve for ethyl malonic acid

\section{RESULTS}

\subsection{Experimental Observations for the Reaction of} Monoalkyl Malonyl Chloride

\subsubsection{Experimental Observations for the Reaction} of Monoalkyl Malonyl Chloride with Solvent:

Monoalkyl malonic acid disappearance was monitored by thin layer chromatography as shown in Figure $4 \& 5$. The concentration of monoalkyl malonic acid is determined from Figure $2 \& 3$.

Monoalkyl malonic acid was reacted with thionyl chloride. Methylene chloride was added in the reaction mass. Samples were taken at regular time interval from time $\mathrm{t}=0$, i.e., before addition of thionyl chloride in the reaction mass. Further, samples were withdrawn at the time interval of 15 minutes. The samples were then spotted on TLC plate to determine the concentration of the monoalkyl malonic acid.

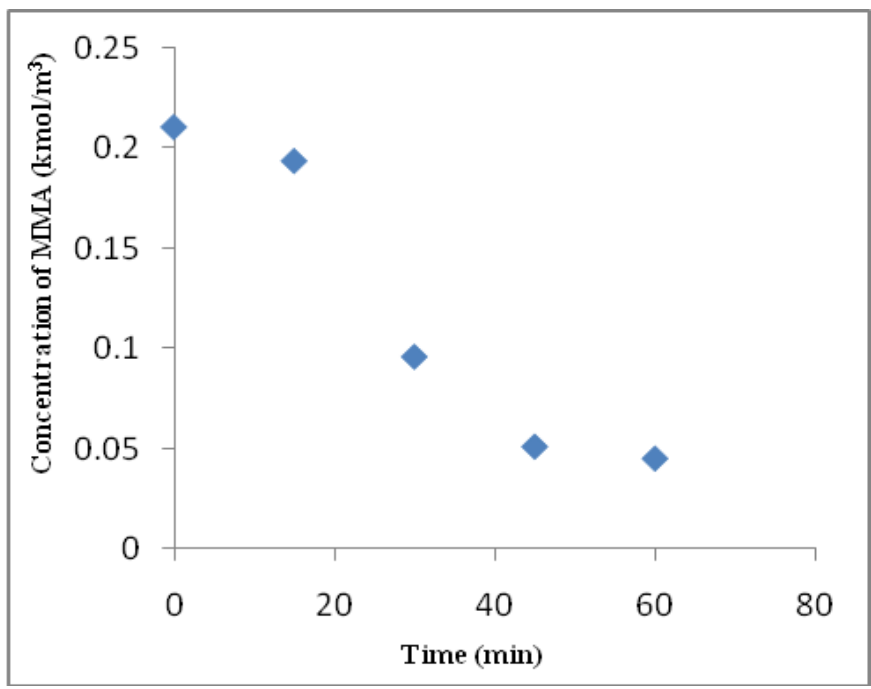

Fig 4: Concentration Vs time curve of methyl malonic acid with solvent 


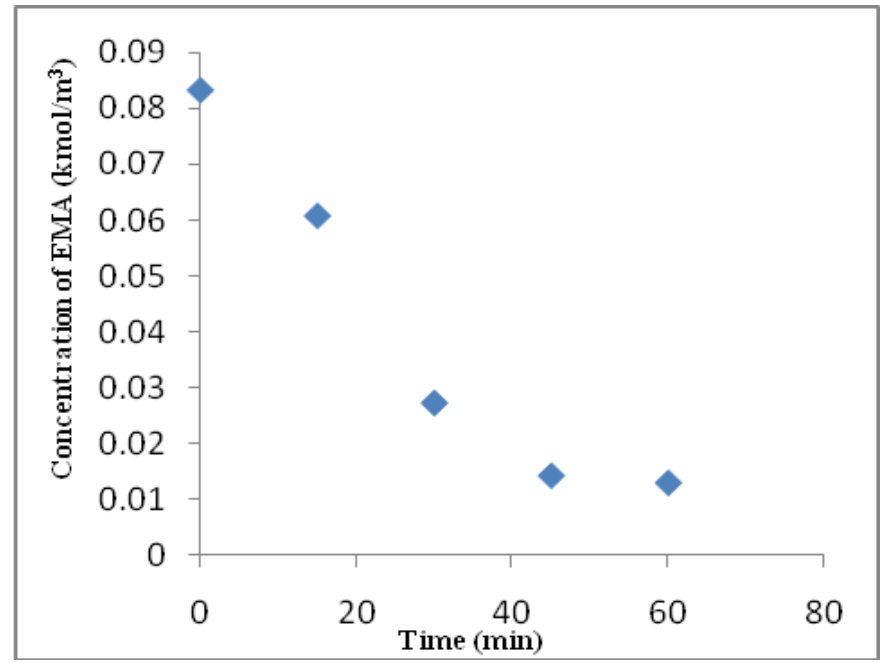

Fig 5: Concentration Vs time curve of ethyl malonic acid with solvent

\subsubsection{Experimental Observations for the Reaction}

\section{of Monoalkyl Malonyl Chloride without Solvent}

Monoalkyl malonic acid disappearance was monitored by thin layer chromatography. The concentration of monoalkyl malonic acid is determined from Figure $2 \& 3$.

Monoalkyl malonic acid was reacted with thionyl chloride. Samples were taken at time $\mathrm{t}=0$, i.e., before addition of thionyl chloride in the reaction mass. Further, samples were withdrawn at the time interval of 15 minutes. The samples were then spotted on TLC plate to determine the concentration of the monoalkyl malonic acid.

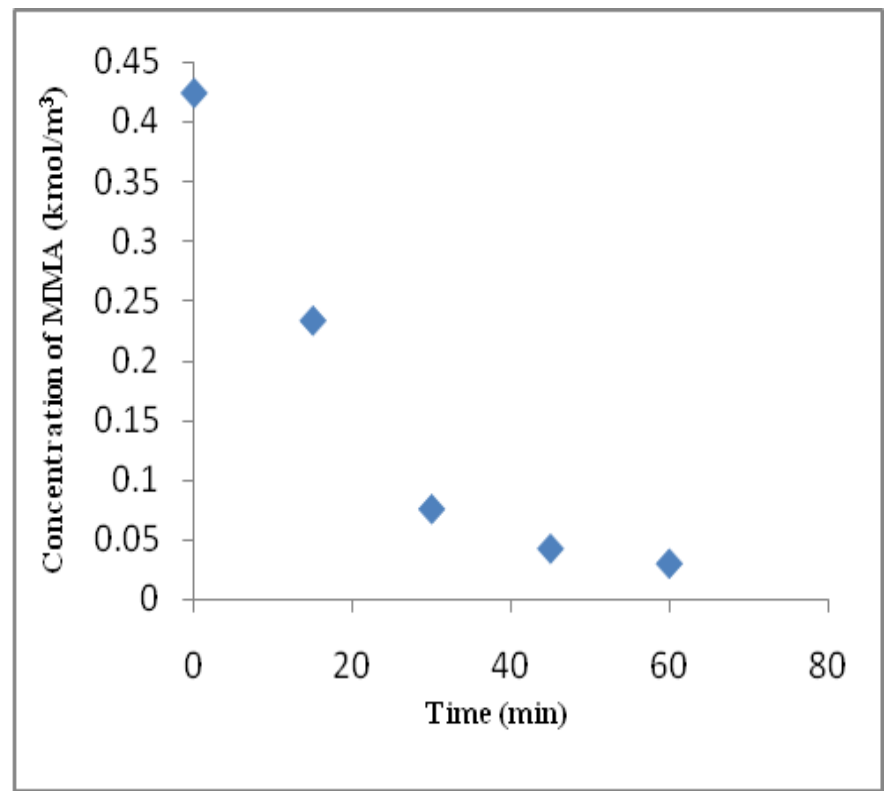

Fig 6: Concentration Vs time curve of methyl malonic acid without solvent.

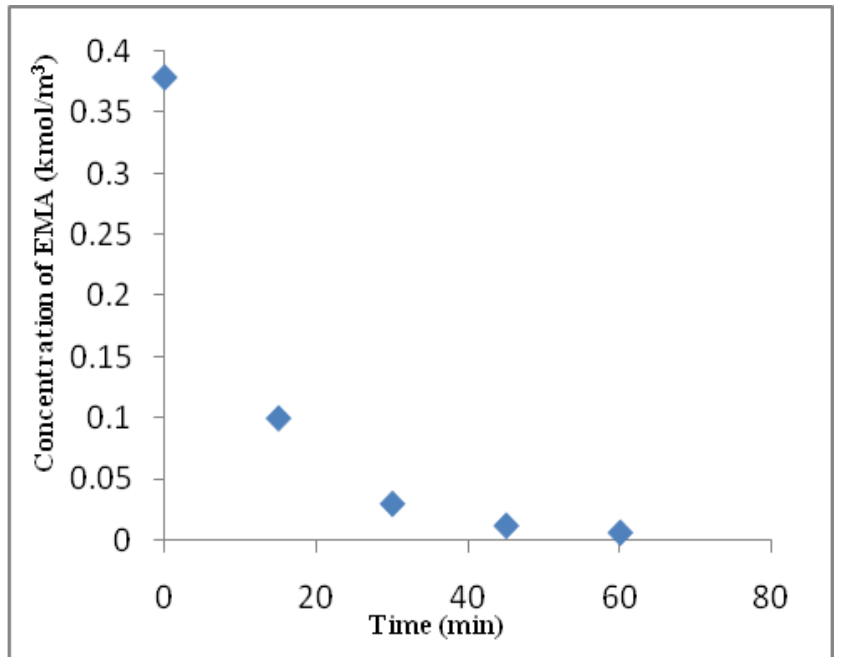

Fig 7: Concentration Vs time curve of ethyl malonic acid without solvent.

\subsection{Conversion}

The conversion of methyl malonic acid in solvent process was found to be $78.67 \%$ and in without solvent process was found to be $93.08 \%$ from the experiments carried out. The conversion of ethyl malonic acid in solvent process was found to be $84.39 \%$ and in without solvent process was found to be $98.23 \%$ from the experiments carried out.

\subsection{Order of Reaction}

The order of reaction was determined by the integrated rate law[7]. The experimental data fitted well for the first order system.

First Order

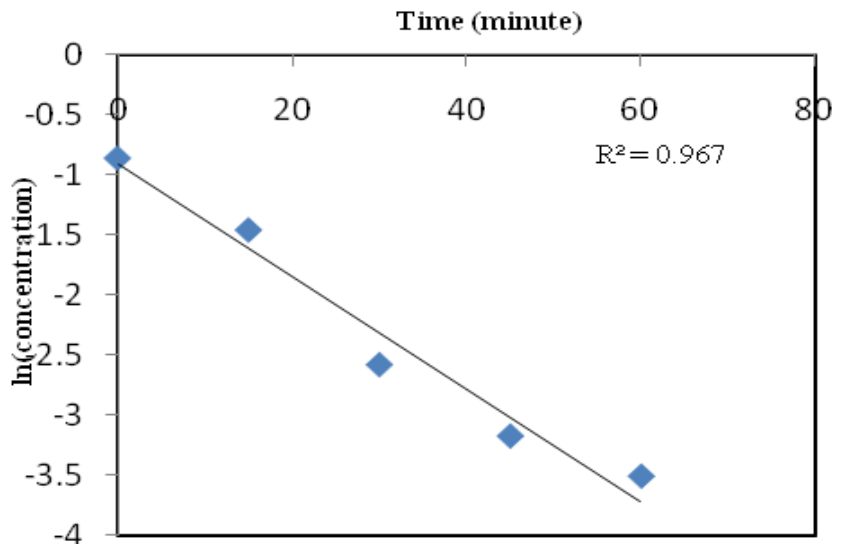

Fig 8: Plot of $\ln$ (concentration ) Vs time.

Hence, the rate equation is written as,

$$
C_{A}=C_{A 0} e^{-h t t}
$$

Where, $\mathrm{C}_{\mathrm{A}}=$ Concentration of thionyl chloride $\left(\mathrm{C}_{\text {thionyl chloride }}\right)$ $\left(\mathrm{kmol} / \mathrm{m}^{3}\right)$ at time $\mathrm{t}$.

$\mathrm{C}_{\mathrm{AO}}=$ Concentration of thionyl chloride $\left(\mathrm{C}_{\text {thionyl chloride }}\right)$ $\left(\mathrm{kmol} / \mathrm{m}^{3}\right)$ at time $\mathrm{t}=0$. 


\section{CONCLUSION}

The order of reaction is determined from experimental data by integrated rate law as first order. The rate equation of the reaction is

$$
C_{A}=C_{A 0} e^{-h t}
$$

where, $\mathrm{C}_{\mathrm{A}}$ is the concentration of thionyl chloride at time $\mathrm{t}$ and $\mathrm{C}_{\mathrm{AO}}$ is the concentration of thionyl chloride at time $\mathrm{t}=0$.

The conversion for methyl malonic acid in solvent process was found to be $78.67 \%$ and in without solvent process was found to be $93.08 \%$. The conversion for ethyl malonic acid in solvent process was found to be $84.39 \%$ and in without solvent process was found to be $98.23 \%$. It has been found that the solvent provides the dilution factor which hampers the extend of conversion of the reactant.The process without solvent shows more conversion.

Methylene chloride is a non-polar, chlorinated solvent [9]. It is non-reactive with the reactant and product of the reaction. It is also compatible with thionyl chloride. It does not affect the reaction conditions. It only provides the dilution effect. It absorbed the exotherm produced during the reaction. It also provided moisture free atmosphere for the reaction. It did not get involved in the reaction. However, its use in the earlier studies was only to dissipate the energy and to provide moisture free atmosphere. In the present study we provided the required inert atmosphere. Hence it is recommended to carry out the reaction without methylene chloride as a solvent and to carry out in solvent free environment. This is also strongly recommendable from the point of view of developing and transferring existing processes to cater to environmental sustainability.

\section{REFERENCES}

[1] Morrison R. T., Boyd R. N., Organic Chemistry, Pearson Education, Inc. $6^{\text {th }}$ edition 1992.

[2] "Process for the preparation of Roquinimex", United States Patent 5912349, Jun 15, 1999.

[3] Process for preparing Potassium monoethyl malonate“, United States Patent 6172257 B1,Jan 9, 2001.

[4] European Patent 2221299 A2,Aug 25, 2010.

[5] Mcmaster L. and Ahmann F. F., " "Action of thionyl chloride on organic acids", the Division of Organic Chemistry of the American Chemical Society, Richmond, Virgini, April 11 to 16, 1927.

[6] Anastas P. T., Warner J. C., Green Chemistry: Theory and Practice, Oxford University Press: New York, (1998).

[7] Chatwal G.R., Anand S. K., Instrumental methods of Chemical Analysis, Himalaya Publishing House, $5^{\text {th }}$ edition (2002)

[8] Levenspeil O.,Chemical Reaction Engineering, John Wiley \& Sons, $2^{\text {nd }}$ edition(1995).

[9] Linstrom, P.J.; Mallard, W.G. (eds.) NIST Chemistry WebBook, NIST Standard Reference Database Number 69. National Institute of Standards and Technology, Gaithersburg MD. http://webbook.nist.gov 